\title{
Recycling in IR, What IR Specialists Can Do to Help
}

\author{
Michael P. Brassil ${ }^{1} \cdot$ William C. Torreggiani $^{1}$
}

Received: 12 February 2019/Accepted: 11 March 2019/Published online: 18 March 2019

(C) Springer Science+Business Media, LLC, part of Springer Nature and the Cardiovascular and Interventional Radiological Society of Europe (CIRSE) 2019

The topic of pollution and global warming has dominated debate within media and government for many years. The current global warming trends are thought likely to be a consequence of the behavior of humans since the mid-twentieth century [1]. The scale of pollution and carbon footprint generated by industry, particularly in rapidly developing economies, is staggering and often leads to a feeling of helplessness and apathy amongst individuals when it comes to personal environmental responsibility [2].

Healthcare and indeed radiology departments contribute significantly to the world's carbon footprint, and the demand for water and electricity to power our hospitals is largely unavoidable, although significant improvements have been explored such as powering down and using "sleep mode" on computer monitors [3] and use of LED lighting [4].

Interventional radiology contributes to a large portion of hospital waste, with many items used containing extensive packaging and single-use items. Recycling and waste limitation is often not a high priority with many interventional radiologists. It is becoming increasingly important that we all contribute to the promotion of recycling and reduction in unnecessary packaging in order to reduce hospital wastage. With a bit of thought and effort, interventional radiologists can make a real difference in reducing waste and promoting recycling.

Interventional radiology has traditionally pioneered modern medicine in offering minimally invasive alternatives to surgical intervention and offering value to patients and hospitals alike while reducing inpatient hospital admissions and length of stay. When it comes to waste and recycling, the healthcare sector is in the midst of a green revolution, and we are at risk of getting left behind. Having a green policy in interventional radiology will make a difference to the quantity of waste we produce and the costs associated with its disposal.

The first step to address is staff education and promoting awareness. In our institution, when we examined our practices, we found that often we had only general waste and risk waste bins available during procedures with staff believing that general waste was actually being recycled. It was clear that staff wanted to contribute positively, but clear guidance and education was required.

We contacted our hospital environmental services manager and requested a site visit. We learned that virtually all of the packaging from our products was recyclable, free of charge to the hospital. Almost all of this packaging had previously

Michael P. Brassil

michaelbrassi187@gmail.com

William C. Torreggiani

William.torreggiani@tuh.ie

1 Department of Interventional Radiology, Tallaght University Hospital, Dublin, Ireland 
been disposed of in the general waste stream at a disposal cost of $€ 130 /$ tonne, and some recyclable material and general waste was disposed of in clinical waste stream at a disposal cost of $€ 813 /$ tonne [5].

In our hospital, a 2010 waste survey found that throughout the hospital, $13.5 \%$ of the general waste surveyed was comprised of recyclable material. A further approximate $22 \%$ of the general waste was comprised of acceptable plastic film and composite packaging. Based on the 2010 annual waste tonnage, it was estimated that 391 tonnes of these materials could be removed from the landfill waste stream by recycling. Based on current waste management costs, this represented an estimated saving to the hospital of up to $€ 33,000$. Additionally $16.5 \%$ of the clinical waste stream was found to consist of packaging and paper that would have been accepted in recycling bags. Based on 2009 annual tonnage, it was estimated that 28 tonnes of material could have been diverted to the recycling stream with savings of up to $€ 20,000$ [6].

Potential pitfalls included having a clinical waste bin near the scrub station, where inevitably non-risk paper towels would be disposed of. Interestingly, we found a difference in up to $60 \%$ of inappropriately segregated waste in cases where the clinical waste bin was physically closer to the interventionalist than the non-risk bin during procedures. Simple practices such as having a recycling bin readily available at the beginning of a procedure and keeping the clinical waste bin further away led to behavioral change and instant results. We found that all staff became enthusiastic and even competitive in their efforts to improve our recycling.

Another observation we made was that the procedure packs provided to us by device companies were often not tailored to our needs. We found that $12 \%$ of PICC set components and $14 \%$ of Port set components were routinely discarded, and in some cases, auxiliary equipment was being used in line with local practices and preferences. We also found that the more expensive equipment and devices usually had more cumbersome and elaborate packaging, which perhaps was unnecessary. We engaged with industry representatives from our top 8 product suppliers who provided us with their environmental and manufacturing policies. In most cases, the companies had firm commitments to recycling and reducing waste in manufacturing. We found that there was widespread interest in our green initiative, and we are engaging with our suppliers to tailor products to our local requirement. In such a competitive market place, cost is no longer the only consideration in product selection.

What can IR specialists do to promote recycling in IR?

1. Explore local recycling policies and adopt them in your daily practice.

2. Encourage colleagues to segregate waste appropriately.

3. Engage with suppliers to minimize unnecessary packaging and tailor products for your needs.

We want to open dialogue on environmental awareness and encourage other interventional radiology departments to question their practices, explore alternatives, and remain open-minded to change. With minimal effort, minor behavioral adjustments, and at the expense of neither money nor time, real results will be achieved and a sense of teamwork and achievement amongst colleagues can be fostered.

Our personal experience with improving environmental sustainability in the IR department has been enlightening, enriching, and rewarding. By reducing, reusing, and recycling, we not only save money, but we can be leaders in the green healthcare revolution.

\section{Compliance with Ethical Standards}

Conflict of interest The above authors have no conflict of interest to declare.

\section{References}

1. Santer BD, et al. A search for human influences on the thermal structure of the atmosphere. Nature. 1996;382:39-46.

2. Pelletier LG, et al. Why do people fail to adopt environmental protective behaviours? Toward a taxonomy of environmental amotivation. J Appl Soc Psychol. 1999;29(12):2481-504.

3. McCarthy CJ, et al. Ecoradiology-pulling the plug on wasted energy in the radiology department. Acad Radiol. 2014;21(12):1563-6.

4. Chawla A, et al. Greening the radiology department: not a big mountain to climb. Can Assoc Radiol J. 2017;68(3):234-6.

5. Reducing waste in Irish healthcare facilities, results, guidance and tips from a waste prevention programme. Environmental Protection Agency 2014. ISBN 978-1-906953-16-4.

6. AMNCH Waste Survey 2010. Prepared by the Clean Technology Centre, Cork Institute of Technology under funding provided by the Environmental Protection Agency.

Publisher's Note Springer Nature remains neutral with regard to jurisdictional claims in published maps and institutional affiliations. 